\title{
DỨBin
}

Technological University Dublin

ARROW@TU Dublin

2018

\section{Social care students' learning in the practice placement in Ireland}

\author{
Fiona McSweeney \\ Technological University Dublin, fiona.mcsweeney@tudublin.ie \\ David Williams \\ Technological University Dublin, david.williams@tudublin.ie
}

Follow this and additional works at: https://arrow.tudublin.ie/aaschsslarts

Part of the Sociology Commons

\section{Recommended Citation}

Fiona McSweeney \& Dave Williams (2018) Social care students' learning in the practice placement in Ireland, Social Work Education, 37:5, 581-596, DOI: 10.1080/02615479.2018.1450374

This Article is brought to you for free and open access by the Social Sciences at ARROW@TU Dublin. It has been accepted for inclusion in Articles by an authorized administrator of ARROW@TU Dublin. For more information, please contact arrow.admin@tudublin.ie, aisling.coyne@tudublin.ie,gerard.connolly@tudublin.ie.

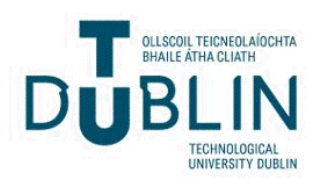




\section{Social care students' learning in the practice placement in Ireland}

\section{Fiona McSweeney \& Dave Williams}

To cite this article: Fiona McSweeney \& Dave Williams (2018) Social care students' learning in the practice placement in Ireland, Social Work Education, 37:5, 581-596, DOI: 10.1080/02615479.2018.1450374

To link to this article: https://doi.org/10.1080/02615479.2018.1450374

曲 Published online: 13 Mar 2018.

Submit your article to this journal $\pi$

Џ Article views: 1067

Q View related articles $\sqsubset$

View Crossmark data

4 Citing articles: 4 View citing articles 


\title{
Social care students' learning in the practice placement in Ireland
}

\author{
Fiona McSweeney (iD and Dave Williams \\ School of Languages, Law and Social Science, Dublin Institute of Technology, Dublin, Ireland
}

\begin{abstract}
The practice placement is a central component of social care education, being seen as where students develop their practice skills, self-awareness and apply theoretical knowledge. This research reports on social care students' experiences of their practice placements, in particular how learning was achieved and what helped learning. An interpretivist approach was used in line with the acceptance of the individuality of students' experiences. A volunteer sample of seventeen students were interviewed individually at the end of their final year in college. The interview transcripts were thematically analysed. Four themes were identified: the need for a balance between autonomy and doing with supervision and observing; the role of all agency staff; the realities of practice and there is always learning. The findings suggest that learning about practice and self occurs in many ways in placement. While supervisors and other staff play a role in assisting student learning by various means participants saw themselves as primarily responsible for their own learning. A key message from this research is that educators cannot regulate everything that happens on placement so students need to be prepared and encouraged to exploit and recognise learning opportunities.
\end{abstract}

\section{ARTICLE HISTORY}

Received 9 November 2017

Accepted 4 March 2018

\section{KEYWORDS}

Social care students; practice placement; learning; supervision; responsibility;

\section{Context}

Social care work involves the provision of professional care, protection and advocacy to individuals and groups who 'experience marginalisation, disadvantage or special needs' (Social Care Ireland, 2016, n.p.). The professions and educational programmes for social work and social care work have evolved separately in Ireland (see McSweeney, 2017a, 2017b). However, they share values such as recognition of marginalisation, enhancing the well-being of clients and empowerment (Irish Association of Social Workers, 2016; Social Care Ireland, 2016). The primary differences between the two professions in Ireland are that social workers have statutory responsibility for case management and protection of vulnerable people (Skehill, 2003; Irish Association of Social Workers, 2016; Social Care Ireland, 2016), while social care work focuses more on the use of 'shared life-space opportunities' and building therapeutic relationships 'to meet the physical, social and emotional needs of clients' (Social 
Care Ireland, 2016, n.p.). While there are commonalities in the standards of proficiency for the two professions in Ireland in relation to knowledge of disciplines such as psychology, sociology, human rights and the use of evidence-based practice there are also differences. Proficiencies for social care work include knowledge of the role of relationships 'as a tool in the delivery of social care'; knowledge of the 'dynamics of relationships'; being able to 'respond appropriately to patterns of behaviours' 'adapt environments to enhance participation and engagement in meaningful life experiences' (Social Care Workers Registration Board, 2017, p. 9). The standards of proficiency for social workers have more emphasis on knowledge of law, the legal system and politics as well as on contributing to social policy. In contrast to the social care proficiencies in building relationships as being the basis for working with clients, the social work proficiencies refer to recognising the legal rights of individuals; managing resistance with involuntary clients; determining 'the nature and severity' of problems; and initiating 'appropriate resolution of problems' (Social Workers Registration Board, 2014, p. 7). The proficiencies for social workers in England share some commonality with proficiencies for social care work in Ireland with a focus on the emotional and developmental aspects of relationships with clients (Health \& Care Professions Council, 2017).

A common factor in the educational programmes for both professions is the centrality of the practice placement. In social care education it is seen as being where students apply theoretical knowledge, develop their practice skills and professional values, understand the working of a social care organisation and become more aware of themselves and their learning needs, through supervised participation in the work of a social care agency (Irish Association of Social Care Educators, 2009). This has commonalities with the aim of the placement in social work in many countries (Lefevre, 2005; Fortune, Lee, \& Cavazos, 2007; Bogo, 2015). Indeed Wilson, Walsh, and Kirby (2008, p. 41) note that social work students in Northern Ireland often complete placements in 'more social care type' settings.

\section{Aim and rationale}

The aim of the research reported here is to explore the views of graduating social care students on how they achieved learning on practice placement and what helped their learning. While practice learning involves a number of stakeholders the students' perspective on the experience is central (Wilson et al., 2008), as they are the future practitioners, whose experiences can inform curriculum development and training (Social Work Reform Board, 2010). While Carpenter (2005) argues it is important to engage students in the evaluation of their own learning the student voice is often less privileged in these discussions (Clare, 2007). While a body of research exists on students' satisfaction with and learning on placement the majority approach data collection using structured questionnaires thus arguably not being as open to students' views. In contrast this research adopted an individual focused interpretivist framework. Interpretivist research is argued to be useful for exploring learning as it 'does not predefine the nature of learning' (Merrill, 1999, p. 47) and opens up 'new possibilities for understanding' (McLeod, 2001, p. 4). Rawles (2016) argues that there is a need for more research which captures individual students' experience. In addition Lymbery (2003) contends practice is complex, ambiguous and uncertain thus requires creativity. Logically so too must be learning to practice, further supporting the need to explore it from an interpretivist approach. 


\section{Literature review}

Due to the lack of literature specifically about social care education, as well as similarities between the professions, as noted above, the literature reviewed includes research on social work education.

While Fortune and Kaye (2003) and Lee and Fortune (2013a) argue that consideration of student satisfaction with placement is important as satisfaction may draw students towards learning opportunities and contribute to motivation, Parker (2006) suggests that student satisfaction with placement does not necessarily indicate student learning. Indeed some research suggests that student satisfaction ratings are not correlated with supervisors' performance ratings in clinical social work (Fortune, Mccarthy, \& Abramson, 2001) and with students' own ratings of their performance in social work (Fortune \& Kaye, 2003). They conclude 'apparently satisfaction is dependent more on the personal and conceptual support given by the field instructor than on the type of hands-on practice that seems important to learning skills' (p. 24).

Students see a supportive supervisory relationship as involving supervisors being available, encouraging and collaborative (Lefevre, 2005), as well as supervisors being open, approachable and honest (Brodie \& Williams, 2013). Good supervision is seen by students as involving collaborative goal setting with their supervisors, the supervisors acting as role models and 'a balance between being supervised and developing autonomy' (Miehls, Everett, Segal, \& du Bois, 2013, p. 131). Contrary to Fortune and Kaye's (2003) finding that satisfaction is not related to learning opportunities, Leferve's (2005, p. 576) participants reported that a supportive relationship contributes to learning as it enables them to question, make mistakes, acknowledge difficulties and 'accept and use critical feedback'. Marlowe, Appleton, Chinnery, and Van Stratum (2015) emphasise supervisors creating a safe place where students can explore their cognitive and emotional reactions to practice, thus developing it.

Alternatively when the supervisor is unpredictable, unconstructive and confrontational a negative relationship is perceived, impacting on the students' self-confidence (Lefevre, 2005; Miehls et al., 2013). Personality differences have been given as a reason for a poor relationship by students (Everett, Miehls, du Bois, \& Garran, 2011). Insufficient supervision leads to dissatisfaction with placement for social work students (Everett et al., 2011; Wilson et al., 2008), as it suggests to students that their learning is not important (Fernandez, 1998). Students also report a poor supervisory relationship as negatively impacting on their learning (Smith, Cleak, \& Vreugdenhil, 2015).

While it has been reported that a supportive supervisor can compensate for difficult relationships with other staff, a good relationship with other staff can compensate for a poor relationship with the supervisor (Wilson et al., 2008). Bogo (2015) discusses the importance of agency staff welcoming students, appreciating their contribution and being invested in student learning. Students in Fernandez's (1998) research said this enhanced their confidence. Working with a variety of people also contributes to students' learning as it allows engagement in different activities and exposure to different approaches to practice (Fortune et al., 2007). Discussions of the reasoning behind professional judgements helps students develop their own style of practice (Rawles, 2016).

Opportunities to observe staff model professional behaviour is found to be related to social work students' satisfaction with placement (Fortune et al., 2001) and their self-rating of skills (Lee \& Fortune, 2013a). Working independently was not associated with increased 
skills with these participants but Fortune et al. (2007) report a significant positive relationship between practising social work skills and students' self-evaluation of competence, as well as satisfaction. A lack of perceived learning opportunities is found to be associated with students' dissatisfaction with placement (Wilson, 2013) and judgements of their competencies (Smith et al., 2015).

Bogo (2015) argues that opportunities to work with clients is essential for learning as it enables students to make sense of their knowledge and generate 'personal meaning out of professional notions'. Working with clients is also a source of feelings of accomplishment (Collins, Coffey, \& Morris, 2010). However Fortune and Kaye (2003), found that the amount of time spent and number of interactions with clients was not related to students' self-reported performance, concluding that this is not an indicator of learning.

Assigning tasks that match the student's ability level is important as Fernandez's (1998, p. 184) participants describe both 'premature confidence in their work' and not being trusted to complete tasks or being given menial tasks as being difficult and demotivating. Parker (2006) points out the need to balance tasks that challenge, but do not overwhelm students, to build their sense of competence and self-efficacy. Rawles's (2016, p. 115) participants valued 'a form of autonomy support', where they were supported as they followed their own initiative. This contributed to confidence as well as intrinsic motivation. Wilson et al. (2008) report that showing initiative is encouraged by a majority of social work supervisors, something that Regehr, Regehr, Leeson, and Fusco (2002) argue will prepare them better for the realities of practice. As the placement progresses Strozier, Barnett-Queen, and Bennett (2000) found that students want to take on more responsibility and are satisfied when encouraged to evaluate their own practice (Fortune et al., 2001).

As well as being the site where students can practise skills and show initiative, placements are viewed as being where students can integrate theoretical knowledge (Fortune \& Kaye, 2003). Providing students with conceptual frameworks for practice is associated with student satisfaction (Fortune et al., 2001; Wilson et al., 2008; Brodie \& Williams, 2013). It is also associated with self-reported skills (Lee \& Fortune, 2013a, 2013b). However, Wilson, Walsh, and Kirby (2007) found that students rate social work theory as being less important in guiding practice than organisational policies. Students have reported that supervisors do not appear to have knowledge of social work theories nor confidence in discussing them (Smith et al., 2015). In contrast social work educators, Vayda and Bogo (1991, p. 271) have argued that students do not see the relevance of classroom learning in relation to their placement, viewing the latter 'as an apprenticeship dissociated from conceptual learning'. Supporting this position, Frost, Höjer, and Campanini (2013, p. 338) note that students found it 'difficult to articulate specific theories'. In contrast Rawles's (2016) newly qualified participants referred to how knowledge from theoretical frameworks was integrated with knowledge of clients to guide professional judgement on their placements, suggesting perhaps that it takes time to integrate theory and practice. This is supported by the findings of Simpson, Mathews, Croft, McKinna, and Lee (2010, p. 736) as their participants 'acknowledged that they required time to reflect and integrate knowledge'.

Lee and Fortune (2013b) point out that the reality of social work practice is usually more complex than examples given in class so students may be challenged in reconciling the reality of practice with the ideal learned in the classroom (Cameron, 2003). Indeed students in Wilson's (2013, p. 597) study pointed out the need for more teaching 'related to real life situations as opposed to theory' and did not feel competent to deal with conflict 
and challenging behaviour. Based on reported stress among students, Maidment (2003, p. 51) suggests that students are helped to recognise that the placement environment 'will include conditions that are both good and not so good' and they are equipped to manage the reality of the agency workplace. Other challenges reported to be faced by students are observing unethical practice (Fernandez, 1998), managing emotions when hearing clients' stories, managing professional boundaries while being empathetic towards clients, feeling powerless to help clients and feeling insecure when they could not 'lean on legislation or clearly articulated principles' in Sweden (Rehn \& Kalman, 2016, p. 13). Grant and Kinman (2013) argue that students may suppress their emotional reactions to situations in practice as they view them as unprofessional. Lam, Wong, and Leung (2007) found that students were challenged by situations that conflicted with their personal values and the realisation of power dynamics in professional relationships. These authors argue that being faced with such conflicts can provide an opportunity for students to go beyond self-focused reflective learning to reflexive learning through the critical exploration of 'underlying values and assumptions' (p. 99) of theory and the system. However they report that students are more likely to focus on self. On the other hand, Simmons and Fisher (2016, p. 463) found from pre- and post-placement measures of cognitive complexity, that students showed an increase in their 'ability to accept the legitimacy of diverse opinions' and a realisation that 'authorities may never find the right answers to complex situations'.

With regard to theories discussed in relation to students' learning on placement, Nixon and Murr (2006) note that typically learning on placement has been underpinned by the principles of adult learning theory, where the student is seen to be actively engaged in their learning and accepts responsibility for it. The role of learning through observation and experiential learning is also apparent in the literature (Fortune et al., 2007; Lee \& Fortune, 2013a) as well as receiving feedback (Lefevre, 2005; Marlowe et al., 2015).

In summary, existing literature on the role of practice placement in students' learning indicates contradictory findings about the relationship between satisfaction and learning, how the supervisor and agency staff contribute to each, the role of observation and practice with clients in learning and the actual use of theory in guiding practice by students. The literature also suggests that experiencing challenges on placement is a source of learning about the realities of the workplace. However previous research has not documented in detail what students say about how they learn on placement and what aids their learning, a gap filled by this study.

\section{Methodology}

An interpretivist approach was used in this study as the aim was to understand the participants' own experiences of how they learned on placement. While participants were provided with questions to guide data collection in the semi-structured interviews these were open-ended to facilitate the participants to give their own accounts.

\section{Institutional context}

In the institution where the research was conducted the educational programme is a three year honours degree involving classroom teaching and practice placements to meet standards set down by Qualifications and Quality Ireland (Social Care Award Standards, 2014). 
1000 hours of practice placement, one in each year of the programme, are completed. Arrangements for placements are made by the college tutors directly with the agencies and learning outcomes are set by the college. The agency decides on the student's supervisor. No stipend is provided although the college provides free supervision training. The student completes a contract, in consultation with the supervisor, early in the placement to identify their learning objectives and their plan for meeting these in relation to the set learning outcomes (for example practice skills, self-reflection and use of supervision, working with others, and knowledge of how theoretical frameworks inform practice). This is reviewed by the college tutor and discussed with the student. A placement assessment form is completed by the supervisor, in consultation with the student, at the end of placement. This assesses the student's progress in relation to the learning outcomes and is graded on a pass/fail basis. College tutors maintain contact with supervisors and students during placement and two tripartite meetings are generally held.

\section{Ethics}

Ethical approval was received from the institution's ethics committee. To ensure informed consent, prior to volunteering to take part, potential participants were provided with written details of the aims of the research (to explore their experiences of practice placements). They were told that recordings and transcripts would be stored on the researchers' personal computers in password protected files, that transcripts would be anonymised when transcribing and personal details would not be revealed in subsequent publications. They were also informed of their right to refuse to answer questions in the interview and to withdraw from the research. At interview participants were reminded of their rights before they signed participant consent forms. After interviews were transcribed verbatim participants were sent a copy of the transcript for their comments and opportunity to remove anything they did not want to be used in the analysis. No deletions were requested.

\section{Participants}

All final year students $(n=42)$ were invited to participate in the research. As the researchers were the students' college tutors they were told to choose who would interview them and asked to contact that person. They were told that participation was voluntary and that non-participation would have no impact on their success in the programme. Seventeen students volunteered, 13 female and 4 male. Their ages ranged from 20 to 49 years, with an average of 24.7 years ( $\mathrm{SD}=7.4$ years). When participants made contact with their chosen interviewer they were emailed the interview schedule and a date was organised for the interview. Interviews were conducted after completion of all academic work, assessment and placement. Students chose the location of the interview, with most conducted in the college.

To address the research questions: (1) how did students learn on placement? and (2) what aided their learning?, participants were encouraged to recount their experiences of their practice placements; the role of the student on placement; their expectations of themselves; others expectations of them; challenges faced and sources of support. 


\section{Analysis}

The interview transcripts were analysed thematically, following the process outlined by Braun and Clarke (2006). Transcripts were first read several times with each line of text coded. Codes were then combined to generate potential themes and quotes from the data assigned to the themes. Each author initially analysed the transcripts of the interviews s/he conducted and then revised the themes together to ensure that they were representative of all participants. Four themes were identified. This process of ensuring consensus between researchers in relation to the themes could be considered to increase the face validity of the data (Guest, MacQueen, \& Namey, 2012).

\section{Findings}

Four themes were identified that captured participants' views of their experiences. These are getting the balance between responsibility and protection as well as doing with observing; the involvement of the agency, other staff and the supervisor for learning; the differences between learning in the classroom and applying it in practice and the opportunities for learning to come in a variety of ways on placement. Central within these themes are the tactics used by the students to ensure that they were learning, what they saw as being learning opportunities and what they learned. In the findings individual participants are identified by $\mathrm{P}$ and the order in which they were interviewed, for example P1 is the first participant interviewed.

\section{Theme 1-Getting the balance right}

This theme refers to supervisors getting an appropriate balance between the level of autonomy and responsibility the student is given and are able for, as well as students balancing taking initiative with standing back and observing.

When participants were comfortable with their level of responsibility placement was viewed positively:

It was push, push, push, push which I liked because they didn’t over push me or I thought I couldn't do it. (P7)

Participants discussed the need to be 'doing' in placement, being allowed some autonomy and direct interaction with clients to learn. Participants did not consider they were learning when they were in a 'minor role' (P15); 'made tea and coffee' rather than being 'involved in real meetings' (P10). Interacting with clients was seen as where the real learning was, in particular 'having an impact' (P15). However some recounted incidents where they were put in a position where they were overwhelmed, suggestive of the need for a balance between autonomy and direct supervision:

I was left with very large numbers of service users on my own once or twice, and that kind of scared me a bit. [...] So like there could have been twenty five or thirty people and I felt like I was out of my depth. It was like I can't, you know, I was overwhelmed. (P16)

When they were not given sufficient work to facilitate their learning participants took the initiative and asked for tasks: 'When I addressed her [supervisor], like I need to kind of see a different aspect of this because I didn't feel like I was learning anything' (P15); 'Saying like you want more. You want to be able to take more responsibility and do more work' (P12). 
Participants spoke about 'making a point of showing that you're doing something' (P4) and pushing themselves beyond their comfort zone to enhance their own learning, particularly in their final year placement:

There was one incident where there was a resident who was under the influence. This was my second week. He was really drunk. I thought, 'I don't really want to approach him' but he looked really down. I went over to him and we sat and had a talk and he started telling me that he was having feelings of self-harm and suicidal ideas. So I think I was apprehensive about doing that but when I actually did I was glad that I did. (P1)

I worked a lot more on initiative this year. I wasn't afraid to put opinions forward and to kind of like address issues. [...] So this year I have just been going in if I thought there was an issue arising I had no problem telling them that one young fella this year told me this year about his coke use, his cocaine use. And I kind of talked to him about that whereas generally I'd get really nervous and clam up and run away from the issue whereas I addressed him on it and I asked him about it. And you know I was kind of getting answers from him instead of just leaving it to the staff. Obviously I told the staff. (P15)

Although participants were cognisant of balancing 'doing' with observing:

Especially this year you are going into work next year hopefully, show the initiative, take responsibilities as well as observing and constantly observing, and you have a fine line between it. You are still stepping back if anything out of your grasp happens, and then you can take the initiative on littler things that might happen. (P14)

Appreciation that a certain time period of shadowing and observing was required to 'become used to their policies' (P5); let the clients 'trust you and get to know you' (P9) and not put 'yourself in a vulnerable position' (P16) was evident too.

\section{Theme 2-'It takes a village'}

This theme refers to the participants' view of the contribution of the placement agency as a whole, not just their appointed supervisor, to their learning. They spoke about expectations of their supervisor and qualities they associated with an effective supervisor. They also emphasised other staff members' contribution to, or inhibition of their learning, both directly and indirectly. Providing structure and consistency about the role of students was seen to be a responsibility of the agency, not just supervisors. While a lack of clarity about the student's role was experienced to be frustrating and initially disempowering it was also seen as an opportunity to take control of their own learning.

All participants referred to positive experiences with supervisors and appreciated that supervisors had other commitments. Factors that inhibited a good working relationship were a perceived personality difference where the supervisor was 'laid back whereas I'm the complete opposite so for a long time I didn't feel like I could approach her' (P3); the perception that the supervisor 'didn't have an active interest in me' (P4); timing of shifts: 'I didn't actually see my supervisor that often because of shifts' (P10) and where specific incidents occurred to impact on availability.

When they considered their supervisor to be available, approachable, interested, provided contingent support and evaluated their practice students were satisfied with placement and felt they were learning:

This placement was great that the supervisor was there all the days that I was there. So it was daily kind of engagement with her. All the time talking about what work I should do and evaluating my work as well. (P12) 
He knows where I would be good and it matches my idea. [...] He was asking me about my strengths. Then he was just reinforcing them. (P2)

Participants also discussed the helpfulness of staff 'who can still remember what it is like to be a student thrown into this strange environment' (P10); who showed them respect 'because when the staff respect you the children are obviously going to respect you' (P14); 'seemed to want me here' (P15) and were approachable: 'It was really, really helpful during placement because I didn't feel that I had just that one staff member to keep going to. That I could kind of go to other people as well' (P9).

Staff were also seen to be a source of learning through exposure to different approaches to practice and viewpoints, which was a source of learning:

You see so many different styles and they all follow the same policy but everyone has a completely different style of working so it was interesting to see that and what works with some styles and what doesn't. (P8)

I remember having a conversation with three staff members [about] the young person being moved to a different unit because certain needs that weren't being met in the unit. All three of them had a different view. It was interesting to see their different reasoning behind it. (P17)

Those that described poorer relationships with their supervisors identified one or more other staff members to use as a model for good practice: "like the way they worked with the kids was fantastic and I kind of took it on myself to just shadow them and look for their feedback' (P17).

Some participants also spoke about their observations of the interaction between staff on placement and how this helped them appreciate good teamwork:

They interacted so well together even with the managers. They were in constant communication with each other, even over the smallest change in one of the girl's programme or even just checking on something that they'd done themselves. (P4)

When there was a lack of structure and consistency about the student role within the agency it made participants 'feel like I was just a nuisance to the staff' (P1), feeling 'lost' and thinking 'maybe I can't do this' (P3). Most took the initiative to remedy this themselves within the placement demonstrating responsibility for their own learning:

Volunteering myself for stuff [...] a lot of it was jumping at the opportunity to be given a task, even like accompanying someone to an appointment. (P1)

\section{Theme 3-The realities of practice}

This theme represents how learning was achieved when students analysed their own preconceptions, the social care system and the place of college learning in the context of practice experiences.

Some participants discussed questioning their assumptions about people and the stories they had heard from others based on their placement experiences:

I was in children's residential. Bit nervous about it but it didn't turn out to be as big a deal. Actually you hear all the horror stories and you take them on board! How do you deal with a 14 year old young fella with a knife [...] and you do have that pre-conceived idea that it's going to happen every day. (P10)

It's funny because people are looking for accommodation. They [clients of a homeless service] don't necessarily want help [to get permanent accommodation]. Some of them I've found are 
quite happy to float in and out. When they have rent they stay in. When they don't they go off. (P9)

As well as the organisation and policies of the care system itself:

I read something somewhere that they should be $30 / 70$, in terms of $30 \%$ paperwork and $70 \%$ with the clients, but depending on what was going on, it was completely reversed. Who is looking after these kids, and they are just left in front of the TV. [...] I brought it up with a few staff members and they were 'you are absolutely right, but this paperwork has to be done. If this isn't filled out then we are in the dog house'. (P17)

Participants also spoke about the differences between the 'ideal' presented in the classroom and the complexity of 'real' practice:

I suppose in college you do hear of the horror stories and how some things didn't work out and possible reasons for pretty serious cases and then I suppose when you're there it's easy to be on your moral high horse but then when you actually go into placement and see these things you can actually kind of visualise it a bit more, why things go wrong or how they go wrong. (P8)

Although, as mentioned above, some participants differentiated between knowledge learned in the classroom and how it was applied in practice, most participants experienced placement as helping them make sense of classroom learning and appreciated the need for practical and theoretical input:

Oh that's why we were learning that or that wasn't as pointless as we thought it was. Just applying theory to practice. So that's why we went to college. (P8)

I don't think you could have theory without practice or practice without theory; you just need them both. (P1)

\section{Theme 4-There is always learning}

This theme encapsulates the range of learning that can be achieved by students on placement in relation to practice and self through completing various tasks and encountering different situations. This suggests that placement was not only a site where learning from the classroom was applied and concretised but a source of learning itself.

Some participants commented on the extra learning placement provided, through administrative work: 'by filing I learned the structure of care plans and risk assessments' (P1); answering clients' queries: 'I found a lot out about different services because people were seeking different things (P6)' or through training:

In second year I got trained in needle exchange, I was really, really happy with that because that's not something I would have learned in college. (P7)

Participants emphasised experiential learning on placement as 'if you are being personally threatened or something like that it's not something you can learn by reading' (P15) as 'until you experience it or observe it you really don't have a clue how you will respond and how your body will respond' (P11). Although some participants experienced challenging behaviour from clients they mainly coped by depersonalising it. Balancing building relationships and professional boundaries took more time:

That whole idea of boundaries; I found that harder to grasp. Especially with the discharge. I found that this year [...] that was in my head for about two days. Because I was getting to know him really well and then when he had gone it was upsetting. It was kind of hard to process in my head it is in the best interests for him to be out of the house. (P14) 
Even a difficult placement experience was seen as being a source of learning:

It was the best learning experience for me by a mile. Because you can go through things and you'll never see challenging behaviour and you never see the team dynamics, they're usually all right. It's fully functioning. Then when you're coming into an environment that's difficult for everybody, not just yourself, that's when you realise you can learn loads. (P3)

While observing poor practice caused frustration it taught students the need to take some responsibility for their own self-care: 'I'm afraid of, that I would become that social care worker who's kind of complacent or burnt out and doesn't take responsibility for their own free time, and for taking a break' (P4).

Placement was also a source of learning about self. Participants discussed: having 'skills to make clients more comfortable in talking about their experiences' (P12); a need 'be more assertive' (P8); to 'calm down and take a step back' (P3) and to 'manage my anxiety' (P5).

Two participants referred to learning about and managing self in relation to gender and culture:

I didn't really think about that as my role as a male worker. But it did come up, some of the service users were uncomfortable engaging with a male worker, especially when they come from the traveller community or the African community. So you had to be aware of that. You have to be aware of your own presence as well, to show yourself as a positive male figure. (P12)

With a client he would not talk to anyone and then when I talked to him, it was like non-stop. He told me everything because we both spoke Arabic. And sometimes they don't want to talk to me at all. I know one of the guys had an issue with me being a woman helping him. It's different though, sometimes they perceive me as being maybe, like 'I'm not taken advice from some little girl' and others were like 'she's like my sister'. (P7)

\section{Discussion}

Findings show the complexity of learning for and in practice, involving knowledge of self, professional skills and managing boundaries in relationship-centred work. In response to the research question of how students learned, participants showed awareness that learning could be achieved in a multiplicity of ways. Learning by observing and talking to staff and completing administrative tasks as well as experiential learning is evident (Fortune et al., 2007; Lee \& Fortune, 2013b). In relation to what aided learning, while support from supervisors and staff was important, participants recognised that ultimately they were responsible for their learning so needed to be self-directed and create and recognise their own learning opportunities.

Participants spoke of wanting to be fully involved in the 'real' work of the agency during their placements while also recognising a need to spend some time observing and shadowing until clients were comfortable with them and they were fully aware of policies. While, as found by Fortune et al. (2001) and Lee and Fortune (2013a), observation of good professional behaviour, at an individual and team level, facilitated learning about professional practice. However observation of perceived poor practice led to a deeper level of questioning about professional responsibility for self-care, indicating reflection. Observation of and discussion with staff led to the appreciation of different styles of practice and reasoning behind decisions, as found by Rawles (2016). This concurs with Simmons and Fisher's (2016) findings that placement assists students in accepting the validity of diverse viewpoints and the ambiguity inherent in practice (Lymbery, 2003). 
Placement was seen to complement classroom learning as well as provide additional learning not covered in college. Although participants were not specifically asked about integrating theory some spoke about placement helping to see the relevance of the theory learned in the classroom, contrary to Vayda and Bogo's (1991) argument. While participants recognised that learning could be achieved by means other than direct work with clients (Bogo, 2015), interaction with clients was viewed as a source of experiential learning and actively sought out. Engaging with clients was seen as valuable in developing and realising skills in building trusting relationships as well as managing their reactions to challenging behaviour. Evidence that experiences on placement facilitates reflection on self, in relation to the impact of ascribed characteristics and personality, is apparent in the findings, as also noted by Lam et al. (2007). As found by Rehn and Kalman (2016) participants here were challenged by their emotional reactions to practice, in particular balancing relationship building and boundaries. Contrary to the argument of Grant and Kinman (2013) that students view their own emotional reactions as unprofessional participants accepted the validity of their feelings and processed them.

From exposure to the reality of agencies participants' assumptions about people and the nature of services were questioned. They also spoke of learning that professional decisions were not as clear cut as policy learned in the classroom, showing evidence of reflexivity (Lam et al., 2007). This did not cause insecurity, as with Rehn and Kalman's (2016) participants, but instead suggested development of a higher level of cognitive complexity as discussed by Simmons and Fisher's (2016).

Students were particularly satisfied when responsibility given was contingent on their capabilities (Parker, 2006), they had an available and approachable supervisor and felt wanted and included in the staff team, as found in other research (Brodie \& Williams, 2013; Wilson et al., 2007, 2008). Supportive supervisors assisted in learning through evaluation of practice and development of skills, as reported by Lefevre (2005). However they also appreciated the busyness of supervisors and agencies and the need to be proactive rather than waiting to be assigned work. Nonetheless feeling that the supervisor was disinterested in their learning frustrated them and impacted on confidence initially (Fernandez, 1998). This did not appear to negatively impact on learning in contrast to the findings of Smith et al. (2015). Participants requested tasks or took them on themselves or worked with other members of staff, as found by Wilson et al. (2008).

Some recognised that exposure to agency difficulties was valuable as it was an opportunity to learn about the realities of practice, necessary to prepare them for the workplace, as also noted by Maidment (2003). Overall while participants appreciated 'a form of autonomy support', common with Rawles's (2016, p. 115) participants, they mainly identified themselves as being responsible for their own learning. They appreciated that to exploit all opportunities to learn they needed to show initiative and challenge themselves, particularly in their final year to be ready for the workplace, as argued by Regehr et al. (2002).

\section{Conclusion}

While somewhat limited by the small sample and the voluntary nature of participation this research extends the body of literature on student learning in placement by illustrating a variety of ways in which students learn about practice and themselves, as well as what they consider helps their learning. In particular, it shows the importance of students being open 
that learning can be achieved in a variety of ways and their role in ensuring that learning is achieved. Another limitation is that the participants' were drawn from one graduating class in one institution so the implications of findings need to be approached cautiously. However there is similarity between findings and those of other research, increasing their validity and supporting an assumption of similarity with other situations or 'fuzzy generalisation' (Bassey, 2001). As Willig (2013, p. 94) argues that acceptance of 'participants' experiences' as being 'at least partially socially constituted' allows generalisation to others from similar cultures. While undoubtedly the use of a survey methodology would permit access to a larger sample the use of individual semi-structured interviews was valuable to allow participants the time and space to give detail of their experiences so how learning was achieved and what assisted it was documented, rather than being limited by specific measurement criteria (Mason, 2009).

Findings from this study that can be used to inform practice education are firstly, there is a wide range of learning that available on practice placement, which is achieved through engaging in different tasks. Hence educators and supervisors should promote openness to and recognition of this in students. This could be emphasised to students during preparation for placement seminars, reiterated during placement visits and perhaps documented in placement related assignments.

Secondly, as Wilson et al. (2008, p. 36) note 'practice learning in social work education involves a complex interaction between students, practice teachers, tutors, educational institutions and agencies, and quality is viewable from a number of different perspectives'. While educators are concerned about getting good quality placements for students (Parker, 2006), Wilson (2013) draws attention to the reality that all placements will have limitations on the experiences that can be achieved. A message from this research is that educators cannot fully control what happens in placement agencies so students need to be prepared for this and urged to recognise and exploit all learning opportunities. The findings of this study suggest that, regardless of perceived quality, when students take responsibility and are self-directed learning is achieved. Hence educators might discuss perceptions of quality with students before and during placement and help them see how they can maximise their learning. This will better prepare students for the reality of working in complex and dynamic practice environments.

Thirdly, while the literature discusses the importance of students being exposed to and role-modelling good professional practice, the findings here suggest that there is also learning in observing poor practice and experiencing difficulties in agencies. Rather than fear of being acculturated into poor practice, participants in this study recognised their own responsibility in maintaining motivation and self-care in their future work and discussed the learning achieved from experiencing difficulties in agencies. Educators could provide opportunities for students through seminars for example, to discuss causes of perceived poor practice and agency difficulties.

While learning contracts and placement assessment forms are undeniably essential to plan and assess learning on placement this approach does not necessarily indicate all the learning, or how it has been achieved by students throughout the process. By allowing students the space to discuss their learning experiences throughout their practice placements this research provides a more nuanced account of how students manage their learning on placement. 
As discussed by Moorhead, Bell, and Bowles (2016), in relation to their research on professional identity formation in newly qualified social workers, participation in research creates opportunities for reflection and learning. Some students in this research spoke of their participation being a source of learning in itself as the interview process contributed to their reflection. This indicates the value of social care educational programmes including safe opportunities for students to openly discuss their experiences during and after placement without fear of 'being branded a 'problem student" (Fernandez, 1998, p. 179).

\section{Disclosure statement}

No potential conflict of interest was reported by the authors.

\section{Notes on contributors}

Fiona McSweeney, $\mathrm{PhD}$, lectures in psychology and research methods and supervises post-graduate research in the Dublin Institute of Technology. Her primary research area is professional social care education. Past and current research focuses on professional identity, practice teachers' views of their role, social care students' transition to practice, students' learning on placement and graduates and practitioners' views of expected competence for new graduates. Her recent publications include Supervision of students in social care education: Practice teachers' views of their role, Social Work Education (2017); Themes in the supervision of social care students in Ireland: Building resilience, European Journal of Social Work (2017); The changing role of the university: A discursive analysis of good teaching and positioning of academics and students in improving the quality of teaching and learning in Europe's higher education institutions, Irish Journal of Academic Practice (2017).

Dave Williams, $\mathrm{PhD}$, lectures in professional practice in social care in the Dublin Institute of Technology. His research interests are the experiences of the biological children of foster parents, challenging behaviour and self-harm and social care education. His recent publications include Editorial, Journal of Social Care, (2017); From dominance to periphery: Residential child care in Ireland, Residential child and youth care in a developing world: European perspectives (2017); Grief, loss and separation: Experiences of birth children of foster carers, Child \& Family Social Work (2017).

\section{ORCID}

Fiona McSweeney (D) http://orcid.org/0000-0002-9329-6896

\section{References}

Bassey, M. (2001). A solution to the problem of generalisation in educational research: Fuzzy prediction. Oxford Review of Education, 27(1), 5-22.

Bogo, M. (2015). Field education for clinical social work practice: Best practices and contemporary challenges. Clinical Social Work Journal, 43(3), 317-324.

Braun, V., \& Clarke, V. (2006). Using thematic analysis in psychology. Qualitative Research in Psychology, 3(2), 77-101.

Brodie, I., \& Williams, V. (2013). Lifting the lid: Perspectives on and activity within student supervision. Social Work Education, 32(4), 506-522.

Cameron, H. (2003). Educating the social work practitioner. Australian Journal of Adult Learning, 43(3), 361-379.

Carpenter, J. (2005). Evaluating outcomes in social work education. London: Social Care Institute for Excellence/Scottish Institute for Excellence in Social Work Education. 
Clare, B. (2007). Promoting deep learning: A teaching, learning and assessment endeavour. Social Work Education, 26(5), 433-446.

Collins, S., Coffey, M., \& Morris, L. (2010). Social work students: Stress, support and well-being. British Journal of Social Work, 40(3), 963-982.

Everett, J. E., Miehls, D., du Bois, C., \& Garran, A. M. (2011). The developmental model of supervision as reflected in the experiences of field supervisors and students. Journal of Teaching in Social Work, 31(3), 250-264.

Fernandez, E. (1998). Student perceptions of satisfaction with practicum learning. Social Work Education, 17(2), 173-201.

Fortune, A. E., \& Kaye, L. (2003). Learning opportunities in field practica. The Clinical Supervisor, 21(1), 5-28.

Fortune, A. E., Mccarthy, M., \& Abramson, J. S. (2001). Student learning processes in field education. Journal of Social Work Education, 37(1), 111-124.

Fortune, A. E., Lee, M., \& Cavazos, A. (2007). Does practice make perfect? The Clinical Supervisor, 26(1-2), 239-263.

Frost, E., Höjer, S., \& Campanini, A. (2013). Readiness for practice: Social work students' perspectives in England, Italy, and Sweden. European Journal of Social Work, 16(3), 327-343.

Grant, L., \& Kinman, G. (2013). 'Bouncing back?' Personal representations of resilience of students and experienced social workers. Practice, 25(5), 349-366.

Guest, G., MacQueen, K., \& Namey, E. (2012). Applied thematic analysis. London, England: Sage Publications.

Health \& Care Professions Council. (2017). Standards of proficiency-social workers in England. London: Health \& Care Professions Council. Retrieved from http://www.hpc-uk.org/assets/docu ments/10003B08Standardsofproficiency-SocialworkersinEngland.pdf

Irish Association of Social Care Educators (2009). Practice placement manual. Retrieved from http:// staffweb.itsligo.ie/staff/pshare/iasce/Placement\%20Manual\%2029mar09.pdf

Irish Association of Social Workers. (2016). About social work. Retrieved from https://www.iasw.ie

Lam, C. M., Wong, H., \& Leung, T. T. F. (2007). An unfinished reflexive journey: Social work students' reflection on their placement experiences. British Journal of Social Work, 37(1), 91-105.

Lee, M., \& Fortune, A. E. (2013a). Patterns of field learning activities and their relation to learning outcomes. Journal of Social Work Education., 49(3), 420-438.

Lee, M., \& Fortune, A. E. (2013b). Do we need more "doing" activities or "thinking" activities in the field practicum? Journal of Social Work Education, 49(4), 646-660.

Lefevre, M. (2005). Facilitating practice learning and assessment: The influence of relationship. Social Work Education, 24(5), 565-583.

Lymbery, M. (2003). Negotiating the contradictions between competence and creativity in social work education. Journal of Social Work, 3(1), 99-117.

Maidment, J. (2003). Problems experienced by students on field placement: Using research findings to inform curriculum design and content. Australian Social Work, 56(1), 50-60.

Marlowe, J. M., Appleton, C., Chinnery, S., \& Van Stratum, S. (2015). The integration of personal and professional selves: Developing students' critical awareness in social work practice. Social Work Education, 34(1), 60-73.

Mason, J. (2009). Mixing methods in a qualitatively driven way. Qualitative Research, 6(1), 9-25.

McLeod, J. (2001). Qualitative research in counselling and psychotherapy. London: Sage Publications.

McSweeney, F. (2017a). Supervision of students in social care education: Practice teachers' views of their role. Social Work Education, 36(1), 26-47.

McSweeney, F. (2017b). Themes in the supervision of social care students in Ireland: Building resilience. European Journal of Social Work, Online First published August, 21, 2017. doi:10.108 $0 / 13691457.2017 .1366428$

Merrill, B. (1999). Gender, change and identity: Mature women students in universities. Aldershot: Asgate.

Miehls, D., Everett, J., Segal, C., \& du Bois, C. (2013). MSW students' views of supervision: Factors contributing to satisfactory field experiences. The Clinical Supervisor, 32(1), 128-146. 
Moorhead, B., Bell, K., \& Bowles, W. (2016). Exploring the development of professional identity with newly qualified social workers. Australian Social Work, 69(4), 456-467.

Nixon, S., \& Murr, A. (2006). Practice learning and the development of professional practice. Social Work Education, 25(8), 798-811.

Parker, J. (2006). Developing perceptions of competence during practice learning. British Journal of Social Work, 36(6), 1017-1036.

Qualifications and Quality Ireland. (2014). Social care work award standards. Retrieved from http:// www.qqi.ie/Publications/Social\%20Care\%20Work\%20-\%20Awards\%20Standards.pdf

Rawles, J. (2016). Developing social work professional judgement skills: Enhancing learning in practice by researching learning in practice. Journal of Teaching in Social Work, 36(1), 102-122.

Regehr, C., Regehr, G., Leeson, J., \& Fusco, L. (2002). Setting priorities for learning in the field practicum. Journal of Social Work Education, 38(1), 55-64.

Rehn, M., \& Kalman, H. (2016). Social work students' reflections on challenges during field education. Journal of Social Work, Online First published June, 12, 2016. doi:10.1177/1468017316654362

Simmons, C., \& Fisher, A. K. (2016). Promoting cognitive development through field education. Journal of Social Work Education, 52(4), 462-472.

Simpson, D., Mathews, I., Croft, A., McKinna, G., \& Lee, M. (2010). Student views on good practice in social work education. Social Work Education, 29(7), 729-743.

Skehill, C. (2003). Social work in the Republic of Ireland: A history of the present. Journal of Social Work, 3(2), 141-159.

Smith, D., Cleak, H., \& Vreugdenhil, A. (2015). "What are they really doing?" An exploration of student learning activities in field placement. Australian Social Work, 68(4), 515-531.

Social Care Ireland. (2016). What is social care work? Retrieved from https://www.socialcareireland.ie

Social Care Workers Registration Board. (2017). Standards of proficiency for social care workers. Dublin: CORU.

Social Work Reform Board. (2010). Building a safe and confident future: One year on-detailed proposals from the social work reform board. London: Department of Education.

Social Workers Registration Board. (2014). Standards of proficiency and practice placement criteria. Dublin: CORU.

Strozier, A. L., Barnett-Queen, T., \& Bennett, C. K. (2000). Supervision: Critical process and outcome variables. The Clinical Supervisor, 19(1), 21-39.

Vayda, E., \& Bogo, M. (1991). A teaching model to unite classroom and field. Journal of Social Work Education, 27(3), 271-278.

Willig, C. (2013). Introducing qualitative research in psychology (3rd ed.). Maidenhead: Open University Press/McGraw Hill Education.

Wilson, G. (2013). Preparing social workers for practice: Re-evaluating student learning needs. Social Work Education, 32(5), 590-606.

Wilson, G., Walsh, T., \& Kirby, M. (2007). Reflective practice and workplace learning: The experience of MSW students. Reflective Practice, 8(1), 1-15.

Wilson, G., Walsh, T., \& Kirby, M. (2008). Developing practice learning: Student perspectives. Social Work Education, 27(1), 35-50. 